\title{
PerCursos
}

\section{Interculturalidade, colonialidade e povo Guarani - a busca da Terra sem Males ${ }^{1}$}

\section{Resumo}

Este artigo tem como objetivo convidar a uma reflexão sobre os processos de colonização sofridos pelos povos indígenas da América Latina, em particular, os guaranis. O artigo se caracteriza como uma pesquisa de caráter teórico-epistemológico e de revisão bibliográfica. Elegemos a intercultura como a perspectiva epistemológica (CANCLINI, 2006) para a construção de um diálogo em que as culturas não se sobreponham umas às outras, mas sim, que dialoguem entre elas com o objetivo de construir novas formas de pensar as relações culturais como processos interculturais. Propomos um conhecimento que privilegie o contato entre a cultura local e a global (GEERTZ, 2009) sem ter como orientação a hierarquização das formas de entender, de fazer e de promover as relações entre as diferentes culturas que se cruzam e entrecruzam. Como reflexão final, trazemos o modo/concepção de viver dos povos Guarani, a concepção mística/religiosa da "busca da Terra sem Males". Partimos do princípio de que a busca da terra sem males transforma o modo como os indígenas guaranis enxergam os percursos da vida cotidiana.

Palavras-chave: Interculturalidade. Povo Guarani. Colonialidade. Terra sem Males.
Sandra Maders

Doutora em Educação pela Universidade Federal de Santa

Maria - UFSM. Professora da Universidade Federal do Pampa Unipampa. Brasil

sandramaders@unipampa.edu.br

\section{Valdo Barcelos}

Phd em Antropofagia Cultural

Brasileira pela Universidade

Federal de Santa Catarina - UFSC.

Professor da Universidade

Federal de Santa Maria - UFSM.

Brasil

vbarcelos@terra.com.br

\section{Para citar este artigo: \\ MADERS, Sandra; BARCELOS, Valdo. Interculturalidade, colonialidade e povo Guarani - a busca da Terra sem Males. PerCursos, Florianópolis, v. 22, n.48, p. 109 - 127, jan./abr. 2021.}

DOI: $10.5965 / 1984724622482021109$

http://dx.doi.org/10.5965/1984724622482021109

\footnotetext{
${ }^{1}$ Grande parte da discussão feita neste artigo foi derivada da Tese de doutorado em Educação, defendida pela autora Sandra Maders, no ano de 2017, pelo Programa de Pós-Graduação em Educação/PPGE na Universidade Federal de Santa Maria/UFSM.
} 


\title{
Interculturality, coloniality and the Guarani people - the search of the Earth without Evil
}

\begin{abstract}
This study aims to invite people to think about the colonization processes undergone by the indigenous peoples of Latin America, particularly the Guarani. The article is characterized as a theoretical-epistemological research and a literature review. We elected interculture as the epistemological perspective (CANCLINI, 2006) to construct a dialogue where cultures do not overlap each other, but rather, dialogue among them to build new ways of thinking cultural relations as intercultural processes. We propose a knowledge that privileges the contact between local and global culture (GEERTZ, 2009) without having as a guideline the hierarchization of the ways of understanding, doing, and promoting the relationships between the different crossing and intersecting cultures. As a final reflection, we bring the Guarani peoples' way/conception of living, the mystical/religious conception of the "search for the Land with no Evil". We assume that the search for the land with no evil transforms how the Guarani indigenous people perceive the paths of everyday life.
\end{abstract}

Keywords: Interculturality. Guarani People. Coloniality. Earth without Evils. 


\section{Introdução}

No texto introdutório do livro intitulado Uma literatura nos trópicos (1978), o escritor brasileiro, Silviano Santiago (2000), cita uma passagem do clássico Tristes Trópicos, de Claude-Léwis Strauss (1908-2009). O fragmento se refere a uma pergunta feita pelos religiosos da Ordem de São Gerônimo, sobre a possibilidade de os nativos latino-americanos terem ou não capacidade para viver por seus próprios meios, caso se fizessem camponeses de Castilha. Vamos à resposta:

Na verdade, talvez seus netinhos possam; além do mais, os indígenas estão de tal modo entregues ao vício que ainda se pode duvidar de sua capacidade; como prova, evitam os espanhóis, recusam-se a trabalhar sem remuneração, mas levam a perversidade até o ponto de presentearem os próprios bens; não admitem repudiar os companheiros que tiveram as orelhas decepadas pelos espanhóis... Seria melhor para os índios que se transformassem em homens escravos do que continuassem a ser animais livres. (LÉVI-STRAUSS, 1978, p. 82)

Há que nos perguntarmos como poderia ter sido diferente a relação entre os recém-chegados portugueses e os povos nativos se, os primeiros não fossem portadores de tanta soberba, arrogância e desprezo pela cultura do outro. Como poderia ter sido rica essa troca entre formas de ver o mundo tão díspares?

Nossa intenção com este texto é apresentar uma reflexão sobre o processo de colonização, imposto pelos invasores europeus, aos povos originários na América Latina com ênfase nos povos que habitavam o que hoje é o Estado Nacional brasileiro. Este texto também deriva da Tese de Doutorado em Educação, defendida pela autora, Sandra Maders, pelo Programa de Pós-Graduação em Educação, da Universidade Federal de Santa Maria em 2017.

Para tanto, estabeleceremos diálogos reflexivos com alguns autores latinoamericanos. Como forma de delimitarmos o campo de nossas reflexões, tomaremos como referência epistemológica a perspectiva dos estudos da interculturalidade propostos por diferentes autores e em momentos distintos no tempo. Também como forma de delimitação, trataremos da cultura dos povos Guarani. 
O desafio de estabelecer interlocução com autores que viveram em lugares diferentes, que partilharam culturas distintas e em épocas muito particulares, não se trata aqui de um fato aleatório. Ao contrário, está em acordo com a proposta central deste texto que é propor uma reflexão sobre o fluir do viver cotidiano (MATURANA; DÁVILA, 2016, p. 32), que valorize os conhecimentos produzidos via orientações científicas sem, contudo, esquecer o papel fundamental, na formação das gentes, dos saberes da experiência e da vivência. Um conhecimento que privilegie a intenção de colocar em contato a cultura local e a global, sem ter como orientação a hierarquização das formas de entender, de fazer e de promover as relações entre as diferentes culturas que se cruzam e entrecruzam.

Esse tipo de relação está referenciada nos princípios da valorização das relações e das interações no estudo das culturas - a interculturalidade -, defendida pelo antropólogo inglês, Gregory Bateson (1904-1980), e aliada à proposição de estudo das culturas do antropólogo cultural, Cliford Geertz (1926-2006), para quem nunca devemos nos esquecer de que toda cultura tem uma base que é local, pois, assim como a técnica da navegação, a perícia da jardinagem, a beleza da construção poética e as disciplinas do conhecimento científico e das ciências sociais, decorrem, também, de artesanatos que são locais. Elas - as culturas - surgem, existem, se fundem e se difundem, a partir de um saber que é, sempre, local. Um desenvolvimento marcado pelo entre-lugar (BHABHA, 2003) das relações interculturais. Relações que passam, segundo esse autor, por uma "tenebrosa sensação de sobrevivência, de viver nas fronteiras do "presente" para as quais parece não haver nome próprio" (BHABHA, 2003, p. 19).

Estamos vivendo um momento de transformações que geram implicações econômicas, políticas, religiosas, ecológicas, étnicas, enfim, culturais, no seu sentido mutante e movediço dos tempos contemporâneos. São diálogos, cruzamentos e entrecruzamentos interculturais (FLEURI, 2003) cada vez mais frequentes e cotidianos que estão a ressaltar as diferenças, pois, como alerta o antropólogo Gregory Bateson (1985, p. 76), estudioso das questões interculturais, para que se crie uma diferença "São necessárias pelo menos duas coisas". Com isso, nos reportamos, também, ao que sugere o pesquisador contemporâneo das culturas híbridas, o argentino radicado no México, 
Néstor G. Canclini, quando este afirma que falar de estudos que envolvem a cultura e os processos de colonização e de dominação cultural é falar a partir das intersecções, é buscar as regiões em que as narrativas se opõem e se cruzam (CANCLINI, 2006; 2003).

Esse autor propõe como alternativa aos processos de aniquilamento de culturas e de etnias, uma relação que se oriente pela perspectiva de privilegiamento das diferenças, do respeito e da escuta do outro, enfim, do entrelaçamento cultural, no qual a cultura é vista como esse entre-lugar sugerido por Bhabha (2003), de relações e construções culturais de limites difusos, marcados por diálogos e disputas que, não raro, levam a conflitos e mesmo guerras antes nunca imaginadas (CANCLINI, 2010). A esse tipo de confronto, Teixeira Coelho denominou de Guerras Culturais (2000). De outra forma, tal cenário de relações interculturais, por vezes paradoxais, pode ser constatado em eventos que marcaram o século XX em decorrência dos processos interculturais cada vez mais influenciados por descentramentos e desconcentramentos da produção e da distribuição da cultura (TEIXEIRA COELHO, 2005, 2008).

Como forma de criar alternativas a essa cultura de confronto, de dominação e de negação do outro, apresenta-se a perspectiva de práticas interculturais articuladas com movimentos socioculturais brasileiros e latino-americanos, com a intenção de analisar dispositivos constitutivos de dialogicidade, sustentabilidade intercultural e de desconstrução de subalternidades (FIGUEIREDO, 2007), particularmente, no âmbito das relações étnicas e culturais, tanto em âmbitos nacionais como internacionais (FLEURI, 2007). Já para o pensador e sociólogo peruano, Anibal Quijano (1930-2018), o continente europeu tomou como seu direito legítimo o controle e dominação cultural dos povos não europeus e, particularmente, os latino-americanos. Para Quijano (2005, p. 108), “A ideia de raça foi uma maneira de outorgar legitimidade às relações de dominação impostas pelos conquistadores. Desse modo, a raça converteu-se no primeiro critério fundamental para a distribuição da população mundial nos níveis, lugares e papéis na estrutura de poder da nova sociedade".

As proposições aqui tomadas como referência filosófica e epistemológica têm o objetivo de promover o que Viveiros de Castro (2015, p. 20) denomina Metafísicas canibais de uma "teoria-prática" nos processos de descolonização do pensamento 
brasileiro e latino-americano. Essa seria, para o autor, uma possibilidade de enfrentar o longo ciclo do colonialismo no continente latino-americano. Tal compreensão pode sustentar a busca de se entender como desconstruir os dispositivos e estratégias de subalternização e de colonialidade (BARCELOS, 2016; CASTRO, 2015; CECHETTI, 2015; MADERS, 2016; MARIN, 2015) inerentes aos processos coloniais, para promover, nas relações interculturais, processos de diálogo crítico e criativo, constitutivos de reciprocidade e de cooperação entre diferentes sujeitos, assim como entre seus respectivos contextos socioculturais - brasileiros e latino-americanos -, sem que a coesão do conjunto anule as diferenças e as singularidades que os compõem na sua diversidade étnica e cultural (FLEURI, 2003).

Nessa perspectiva, a interculturalidade, proposta por Fornet-Betancourt (2015), autor latino-americano peruano, seria como uma janela que permitiria abrir espaço para um olhar em direção ao cenário amplo que compõe cada cultura. Essa busca se alinha a outra proposição generosa de sociedade: a busca da Sustentabilidade das relações sociais entre os diferentes sujeitos nos seus respectivos cenários e contextos culturais. Sobre Sustentabilidade e Interculturalidade, ressaltamos a importante obra intitulada Canibalia, canibalismo, antropofagia cultural y consumo em América Latina, de Carlos Jáuregui (2005). Nessa obra, com a qual foi agraciado com o Prêmio Casa das Américas (2005), o autor dedica o capítulo final ao tema da sustentabilidade, de forma indireta, na medida em que o trata por meio de denso estudo dos hábitos de consumismo moderno exacerbado e sua forma perversa de implementação no continente latino-americano. Para o autor, essa forma desmedida de consumo é como uma sofisticação material e simbólica do processo de colonialidade imposto aos povos ameríndios.

Ao refletir sobre a interculturalidade e a colonialidade em sua Tese para professor Titular, Figueiredo assegura que os estudos e pesquisas do peruano Aníbal Quijano (1991) sobre a Colonialidade/Modernidade se alargaram desde os Estados Unidos, que se constituíam em, 
estudos se integraram à outra emergente corrente de pesquisa a cerca da Interculturalidade, que também se estendem desde o berço do eurocentrismo etnocêntrico até nós. (FIGUEIREDO, 2020, p. 111)

Segundo Figueiredo (2020, p. 114), ao chegarem à América e ao Brasil, essas proposições adquirem outros contornos, adquirem novas formas de se apresentar e "incorporam os conhecimentos acerca da colonialidade e, com as reflexões que ocorrem no Equador, chegam com força e vigor para reconfigurar a interculturalidade e a colonialidade colorindo-a com uma perspectiva crítica", ao se relacionar com os movimentos sociais dos povos latino-americanos". Figueiredo (2007, p. 98) vai além e afirma que “A 'colonialidade' se caracteriza por um padrão de poder que deriva, na percepção de Quijano (2005), de uma classificação social hierarquizante da população mundial pautada pela ideia de raça". Para Fleuri (2013, p. 59), coloca-se um desafio urgente para o conjunto da humanidade nesse século, qual seja: "A realização das relações interculturais". Ao mesmo tempo, esse autor alerta para o fato de que construir essas relações de interculturalidade e de cooperação entre as culturas não é algo fácil. Ao contrário,

É um processo permeado de conflitos e de radicais acontecimentos, como "Guerras, genocídios, processos de colonização e dominação. Entender tais processos de relações interculturais torna-se a condição para compreender e desconstruir as lóticas que conduzem à destruição ou à sujeição mútua. Mais que isso, para descobrir as possibilidades criativas e dialógicas das relações entre grupos e contextos culturais diferentes". (FLEURI, 2013, p. 59, grifo nosso)

Constata-se, assim, que as questões interculturais, hoje, se dão em níveis que não se delimitam apenas aos aspectos relacionados às relações entre estrangeiros. Segundo Canclini (2009), a própria ideia de “estrangeria” passa por um processo de mudança. Nos apoiamos, mais uma vez, na compreensão defendida por esse autor que vê relações de "estrangeria" mesmo dentro da mesma nação. Sobre os diferentes modos de ser estrangeiro nos tempos atuais, esse autor assim se manifesta: 
O estrangeiro não é só aquele que está longe ou do outro lado da fronteira, pode ser aquele que está bem próximo a nós e desafia nossos modos de percepção e ressignificação. Pode-se sentir maior estranhamento diante daqueles em que em sua própria sociedade reivindicam com ênfase um particularismo que em relação com os outros da mesma profissão em países distantes, ou que compartilham formas internacionalizadas de consumo. (CANCLINI, 2009, p. 05)

O caso dos povos indígenas na América Latina em geral, e no Brasil em particular, é um desses exemplos de sentir-se "estrangeiro" dentro de seu próprio território de origem. É sobre essa questão que nos debruçaremos nos momentos a seguir deste texto.

Neste texto trataremos do caso, em particular, da etnia Guarani que, por ocasião da chegada dos portugueses, por volta do ano de 1500, habitavam a América Latina e o Brasil. Era um povo com a mesma origem, e cultivavam práticas comuns de viver. Por exemplo, causaram grande surpresa aos espanhóis quando esses chegaram a Assunção, hoje capital do Paraguai, pela sua agricultura diversificada e de grande capacidade produtiva. Era tão vasta sua produção agrícola que havia grandes excedentes os quais eram consumidos em festas e mesmo partilhados com outros povos. Diga-se, uma prática totalmente estranha aos colonizadores recém-chegados.

\section{Povo Guarani e colonialidade - o sonho da terra sem males}

Singular e assombroso o destino de um povo como os Guarani! Marginalizados e periféricos, nos obrigam a pensar sem fronteiras

Tidos como parcialidades, desafiam a totalidade do sistema. Reduzidos, reclamam cada dia espaços de liberdade sem limites Pequenos, exigem ser pensados com grandeza. São aqueles primitivos cujo centro de gravitação já está no futuro. Minorias, que estão presentes na maior parte do mundo. (MELIÀ, Bartomeu) 
O historiador, sociólogo e escritor brasileiro Paulo Prado (1869-1943), segundo consta na literatura, foi quem teve, junto com sua esposa Marinette Prado, a ideia inicial de criação da "Semana de Arte Moderna de 1922". Esse historiador busca entender a constituição da sociedade brasileira a partir de suas raízes históricas e culturais. Seu livro Retrato do Brasil - Ensaio Sobre a Tristeza Brasileira, publicado no ano de 1928, se tornou uma obra muito polêmica na época e faz ecos ainda hoje. Uma passagem da obra dá um pouco a dimensão da dificuldade de entendimento, por parte dos europeus colonizadores, da cultura em que viviam os povos nativos.

Prado narra que "Uma indígena abandonada pelo amante europeu com quem vivera longos anos, vendo-o partir numa caravela de passagem, matou o filho comum, cortou-o em duas partes e lançou uma destas ao mar como que entregando ao homem a porção que lhe pertencia. A bordo perguntaram a este colonizador português quem era essa mulher, ao que respondeu: não é ninguém, é uma índia sem importância" (PRADO, 1928, p. 45). Os colonizadores, via de regra, não reconheciam nos ameríndios nada de humanidade. Ao contrário, os consideravam incapazes de sentimentos como afeição e amor. As uniões que por vezes aconteciam entre o colonizador e uma mulher indígena, por exemplo, nada mais eram do que uma união baseada na animalidade. Com certeza daí decorre a resposta do colonizador: "Uma índia sem importância”. As mulheres indígenas eram vistas como meras "importunadoras dos brancos" em suas redes.

Seria no mínimo ingenuidade imaginar que décadas de relações coloniais de dominação e de consideração do outro - o povo ameríndio - como alguém não humano não teriam consequências que se arrastariam no tempo. Diga-se que ainda hoje se pode perceber, em várias manifestações de componentes da sociedade brasileira, resquícios dessa visão colonialista e de desprezo pelas culturas dos povos originários.

Uma das principais características dos Guarani, e talvez a mais abordada na etnologia, diz respeito à sua permanente mobilidade. Segundo Melià (1987, p. 294), "a migração, como história e como projeto, constitui um traço característico dos guaranis". Wilson Changaray nos dá uma breve referência de como é a filosofia de vida dos povos indígenas Guaranis: “esse amor, estima, carinho, solidariedade, expressada em 
sentimento ao próximo, que permite superar e desprender-se do ser mesquinho e individualista" (informação verbal).

Esta terra livre, independente e soberana tem que se basear nos princípios fundamentais indígenas. Princípios que superam os interesses pessoais e transcendem e abraçam as esferas do social econômico, cultural e político.

Estes princípios são a essência fundamental do ser Guarani, como a busca incessante da Terra Sem Males e da Liberdade. Mas, quem me responde? ... Nem Deus me responde quando vou ser livre...!!!

Nossa essência é de ser sem dono ... o Deus nosso é a Natureza e não a Lei.... Princípios que impregnam o ser social, como a Mboroaiu, Mborerekua, Yoparareko, esse amor, estima, carinho, solidariedade, expressada em sentimento ao próximo, que permite superar e desprender-se do ser mesquinho e individualista. (Informação verbal)

Segundo levantamentos arqueológicos, a migração indígena teve início muitos séculos antes da criação dos Estados Nacionais e, por volta dos séculos I e II depois do nascimento de Cristo (D.C.), historiadores calculam que, no início da invasão europeia ao Continente (1492), a população indígena girava em torno de um milhão e meio a dois milhões de pessoas, distribuídas em aldeias de trezentos a dois mil habitantes. Ao longo dos últimos 500 anos, os povos indígenas têm criado e recriado suas estratégias de resistência, ora enfrentando forças militares, como os exércitos imperiais de Espanha e Portugal ou, como há pouco, contra venezuelanos; ora encontrando aliados na sociedade envolvente, ora simplesmente se dispersando. Contra todas as formas de dominação (educativa, militar, econômica e religiosa), o povo indígena foi capaz de manter seu espírito livre ao transformar em escudo de proteção o ininterrupto processo de transmitir de geração para geração sua língua e sua cultura, bem como de ter sua principal defesa na filosofia que é a busca pela Terra Sem Males (Yvy marã e'ỹ ).

Segundo o professor indigenista Porto Borges,

a busca da chamada Terra Sem Mal é uma constante no jeito de ser e da concepção de mundo do povo Guarani. É um lugar intocado onde não existe nem rivalidades, violência e falta de reciprocidade. Um espaço mítico onde o teko porã ("bom proceder") predomina em relação ao 
teko marã ("mal proceder") e o mba'e meguã (“coisa má”) simplesmente inexiste. (BORGES, c2021, grifo do autor)

As representações simbólicas de um povo, fazem parte da cultura na qual estão inseridos. De forma não diferente, "A Terra sem Males", segundo Luana Barth Gomes (2014), é uma narrativa sagrada Guarani que, motiva os integrantes desse povo na busca de um espaço onde realmente possam viver seu Nhande Reko, ou seja, seu modo de ser. Segundo Balandier (1997, p. 26), “o mito trabalha na esteira da ação, passa por cima dos homens para se realizar, estabelece sua relação com as potências simbólicas das quais eles pensam ter apoio, ele alimenta a palavra 'quente', que dá a certeza que o mundo pode e vai mudar". Os familiares seguiam os Karaí em busca de um espaço melhor para se viver, onde houvesse fartura e não existisse maldade. Segundo Clastres,

Sabe-se que os tupis-guaranis estavam tão profundamente imbuídos da realidade geográfica do seu paraíso que sempre estavam dispostos a empreender a sua procura, tão grande era a certeza que, se não o descobrissem onde supunham ser seu lugar, ou caso a marcha acabasse levando-os a algum obstáculo intransponível que os forçasse a se deter [...] não hesitavam em partir novamente, numa outra direção. (CLASTRES, 1978, p. 66)

Os povos indígenas, apesar de terem sobrevivido à devastação colonial, ocupam o imaginário das pessoas em muitos países latino-americanos como "invisíveis". Os indígenas permanecem praticamente invisíveis para todos, especialmente aos olhos dos que querem excluí-los de nossa história. Como sugere Viveiros de Castro,

A impressão que tenho é que o "Brasil" até bem pouco não queria nem saber de índio, e sempre morreu de medo de ser associado "lá fora" a esse personagem, que deveria ter sumido do mapa há muito tempo e virado uma pitoresca e inofensiva figura do folclore nacional. Mas os índios continuam aí, e vão continuar. (CASTRO, 2006, p. 84)

Como poderíamos começar a mudar nossa percepção mesquinha e arrogante e passarmos a contribuir de maneira significativa para uma mudança ontológica em relação aos povos indígenas? Poderíamos começar a refletir sobre o modo como as crianças 
indígenas são educadas. Pois, a partir daí passaríamos a compreender como, essa busca da Terra sem Males se transforma em uma busca filosófica de um modo de ser do povo Guarani.

Para os indígenas, todos os processos de aprendizagem/conhecimento se dão à medida que cada criança ou adulto se desenvolve por si só dentro de um conjunto de relações com os outros, sendo autônomos, mas, pensando em um bem maior. Suas práticas educativas oportunizam a consciência de se ver como membro de um todo, integrantes e criadores. Teixeira (2006, p. 163) apud Bergamaschi (2011, p. 140) observa que entre os Guaranis, o visível e o invisível se combinam numa educação que não nega os sentidos,

O invisível é aquilo que desperta no coração, na imaginação, na memória, quando tocamos, quando vemos, quando cheiramos, quando suamos, quando comemos, quando ouvimos e que vai orientando toda a base da inteligência. [...] "Fala de seu Adolfo: A aprendizagem vem da memória dos que escutam". (TEIXEIRA, 2006, p. 163 apud BERGAMASCHI, 2011, p. 140)

Com essa citação, podemos perceber como os processos de aprendizagem na cultura dos povos indígenas guaranis não se separam de suas vidas. O entrelaçamento do aprender/viver é natural e permanente. Outro aspecto importante a destacar na educação indígena, são os espaços ritualísticos de educação, nos quais as crianças são educadas em um mundo espiritual e sagrado, dentro de uma relação de confiança e respeito pelos demais. Segundo Toro apud Moraes (2008, p. 68), os sentimentos produzidos a partir da vitalidade são de alegria e entusiasmo e, esses, por sua vez, geram, como evolução humana, a experiência de autonomia e êxtase, desencadeando sentimentos de ternura, de amizade e amor. Nas sociedades indígenas, o ensinar e o aprender são ações mescladas, incorporadas à rotina do dia a dia, ao trabalho e ao lazer, e não estão restritas a nenhum espaço específico.

O ato de conhecer, dentro da concepção Guarani, passa pelo percurso do autoconhecimento; na verdade não se separam. O corpo é um mediador na apresentação 
desse conhecimento. Corpo nu, corpo vestido, vergonha, emoção, alegria, tristeza, alma, são categorias relevantes na construção do caminho-conhecimento Guarani (BERGAMASCHI; MENEZES, 2009, p. 72). Os indígenas compreendem o sentido da cadeia da vida, do fluir do viver. "Um sistema de conversação é, portanto, um sistema não linear que não se rege por uma linearidade causa-efeito, mas o efeito rebate sobre a causa criando um sistema fechado que se auto alimenta". Os indígenas mantêm um sistema filosófico no qual a questão fundamental é como as coisas chegaram a ser o que são e, não a sua essência. Podemos observar que o fundamental está no "caminhar", no processo e nunca no fim em si.

No livro Educação Ameríndia, a autora Ana Luísa Teixeira descreve este processo de encontro contraditório com os Guaranis como um encontro,

De muita satisfação, mas, também, de apreensões. Sentimos hoje que a convivência é alegre, marcada pela aceitação, carinho e amizades que surgiram. Conhecer os Guarani em suas aldeias foi adentrar num universo desconhecido em que a diferença se impõe na paisagem, nos cheiros, na língua, nas formas contundentes de dizer que estamos em outro território, cujas relações estão marcadas por muitas incompreensões. (TEIXEIRA, 2009, p. 29)

Esse olhar ao diferente se dá desde o lugar de onde estamos e somos. Essas diferenças que se chocam com a cultura Guarani poderiam parecer, à primeira impressão, um desvio aos nossos "olhos ocidentais" de ver o mundo, num desencontro de costumes. Por outro lado, poderia ser um momento de reflexão/ação sobre nossas ações.

Nesta mesma direção é importante o que sugere Fleuri (2004), quando afirma que para além de uma compreensão rígida e disciplinar e normatizadora da diversidade das culturas "Emerge o campo híbrido", fluido, polissêmico, ao mesmo tempo trágico e promissor da diferença, que se constitui nos entre-lugares (BHABHA, 2003, p. 85) e nos entreolhares das enunciações de diferentes sujeitos e identidades socioculturais (FLEURI, 2004, p. 34). 
Poderíamos assim, sugerir que "A Terra sem Males" seria um caminho para se começar a pensar na mudança da visão reducionista que temos em relação aos povos indígenas, como sugere Clastres (1978, p. 113), “a Terra sem Mal: um espaço sem lugares marcados, onde se apagam as relações sociais, um tempo sem pontos de referência, em que se abolem as gerações".

\section{Considerações finais}

Ao compreendermos que vivemos em uma sociedade marcada por conflitos, pela violência, pelas ocupações territoriais e desmatamentos já daremos um passo importante rumo à compreensão da profundidade e da significação cultural da dimensão mítica religiosa da filosofia do povo Guarani, orientada para a busca da "Terra sem Males", pois,

[...] a busca da "Terra-sem-Mal" e de uma "terra nova" estrutura marcantemente seu pensamento e suas vivências; a "Terra-sem-Mal" é a síntese histórica e prática de uma economia vivida profeticamente e de uma profecia realista, com os pés no chão. Animicamente o guarani é um povo em êxodo, embora não desenraizado, pois a terra que procura é a que lhe servirá de base ecológica, amanhã como em tempos passados. (MELIÀ, 1989, p. 294)

Gostaríamos de enfatizar, com essa citação, justamente o ponto que consideramos fundamental neste artigo, ou seja, pensarmos em uma forma de dialogar, de encontrar pontos que coexistam com essa cultura, que não queiramos pensar e ou agir como os indígenas, mas, sim, encontrar pontos em comum, para o início da conversa. E que dessa conversa surja a possibilidade de um diálogo intercultural. Isso seria construirmos conhecimentos que nos possibilitariam, nas diversas situações do cotidiano, dialogarmos com as diferenças e não excluí-las. Nestes diálogos interculturais se criariam espaços de reflexão e ação/criação. Para Geertz (2009, p. 97), a cultura precisa ser vista como um contexto, algo por meio do qual os processos, os comportamentos sociais, podem ser descritos, por exemplo, pelos antropólogos, sociólogos, enfim, pelos estudiosos das relações culturais. Esse pensador vai adiante em sua reflexão e sugere que 
é desta relação de conversação intercultural recíproca, e, num certo contexto, que o olhar para a forma como o outro nos olha, pode nos ajudar a entender quem somos e que lugar ocupamos nesta relação, pois, o fato de ver-nos,

Como os outros nos vêm pode ser bastante esclarecedor. Acreditar que outros possuem a mesma natureza que possuímos é o mínimo que se espera de uma pessoa decente. A largueza de espírito, no entanto, sem a qual a objetividade é nada mais que autocongratulação, e a tolerância apenas hipocrisia, surge através de uma conquista muito mais difícil: a de ver-nos, entre outros, como apenas mais um exemplo da forma que a vida humana adotou em um determinado lugar, um caso entre casos, um mundo entre mundos. Se a antropologia interpretativa tem alguma função geral no mundo, é a de constantemente nos re-ensinar esta verdade fugaz. (GEERTZ, 2009, p. 30)

Ao mesmo tempo em que construímos uma cultura, ela também nos constrói. Estamos inseridos neste processo que acontece todos os dias, todas as horas, em todos os nossos movimentos. O exercício da educação intercultural abre espaço para esse diálogo e conhecimento do outro. A ela não interessa apenas conhecer o estranho, o diferente, mas, entender e refletir sobre a relação existente entre estes. A educação intercultural, mais que conhecer a multiplicidade de culturas, considera o modo próprio de cada grupo social ver e interagir com a realidade (FLEURI, 2002). Da mesma forma, sugere a valorização do sujeito entendendo-o como produtor de sua cultura, pois, como bem nos coloca (FLEURI, 2002) a cultura não existe abstratamente, ela é construída pelas pessoas nas diferentes formas como vivem e estabelecem suas relações.

Sugerimos, assim, que comecemos a parar e pensar em uma maneira de dialogar com os povos indígenas, reconhecendo a legitimidade de seus modos de ver o mundo e de viver seus mundos e sonhos. Ou seja, reconhecê-los como parte integrante, como formadores de uma cultura particular. A construção do bem viver passa, necessariamente, pela harmonia de nossa psique e nossa biologia, enfim, passa pela nossa harmonização ecológica no mundo que vivemos.

O bem estar no mundo que vivemos passa, pela compreensão sincera e generosa de que não precisamos ser perfeitos. Que cometemos equívocos. Que podemos nos enganar e pedir desculpas. O caminho do bem estar está na escuta, na conversa/diálogo, 
na reflexão generosa e não no desamor, na busca do controle e da dominação e dos fundamentalismos de diferentes tipos e origens.

Entendemos que, dependendo do tipo de conhecimento que escolhermos produzir, esse conhecimento terá a grande qualidade de nos fazer reconhecer quando não estamos no bom caminho, algo na perspectiva das ideias pautada na Terra sem Males, e, generosamente, mudar de opinião e nosso modo de viver o cotidiano. Mudar de caminho. Sabemos que qualquer que seja o caminho que escolhermos, será ele que nos orientará na direção de nossa transformação espiritual, biológica e cultural.

O caminho da Terra sem Males, sonhado pelo povo Guarani, pode ser uma importante pista para o caminho do bem estar, mesmo em tempos tão sombrios e de geração de tantos discursos e práticas de ódio.

\section{Referências}

BALANDIER, Georges. O contorno: poder e modernidade. [Lisboa]: BERTRAND, 1997.

BATESON, Gregory. Passos hacia uma ecologia de la mente: una aproximación revolucionária a la autocomprensión del hombre Buenos Aires Editorial Planeta, 1985.

BERGAMASCHI, Maria. A.; MENEZES, Luiza. A. Educação ameríndia: a dança e a escola Guarani. Santa Cruz do Sul: EDUNISC, 2009.

BHABHA, Homi. O local da cultura. Belo Horizonte: Ed. UFMG, 2003.

BORGES, Paulo Porto. Em busca da terra sem mal. Terra Sem Males: jornalismo independente, [s.I.], c2021. Disponível em: https://www.terrasemmales.com.br/embusca-da-terra-sem-mal(...). Acesso em: 01 out. 2020.

CANCLINI; Nestor. Consumidores e cidadãos. Rio de Janeiro: UFRJ, 2006.

CANCLINI, Nestor G. La sociedad sin relato: antropología y estética de la inminencia. Buenos Aires: Katz Editores, 2009.

CANCLINI, Nestor C. Extranjeros en la tecnologia y en la cultura. Buenos Aires: Ariel, 
2010.

CASTRO, Eduardo V. de. Encontros. Rio de Janeiro: Beco do AZOUGUE, 2006.

CASTRO, Eduardo V. de. Metafísica canibais: elementos para uma antropologia pósestrutural. São Paulo: Cosac \& Naify, 2015.

CLASTRES, Hélène. Terra sem mal. São Paulo: Brasiliense, 1978.

CECCHETTI, Elcio; PIOVEZANA, Leonel (org.). Interculturalidade e educação: saberes, práticas e desafios. Blumenau: Edifurb, 2015.

FIGUEIREDO, João. B. A. Educação ambiental dialógica. Fortaleza: Edições UFC, 2007.

FLEURI, Reinaldo M. Intercultura e movimentos sociais. Florianópolis: NUP-UFSC, 1998.

FLEURI, Reinaldo M. Intercultura e educação. Revista Brasileira de Educação-ANPEd, São Paulo: Editores Associados, n. 23, p. 32-37, 2003.

FLEURI, Reinaldo M. Educação intercultural: desconstrução de subalternidades em práticas educativas e socioculturais. Florianópolis: UFSC: CNPq, 2007. (Projeto Integrado de Pesquisa, processo CNPq 301810/2006-0, vigência 2007-2010).

FLEURI, Reinaldo M. Relações interculturais, diversidade religiosa e educação: desafios e possibilidades. In: FLEURI; OLIVEIRA; HARDT; CECCHETTI; KOCH, (orgs.). Diversidade religiosa e direitos humanos: conhecer, respeitar e conviver. Blumenau: EDIFURB, 2013. P. 48-59.

FORNET-BETANCOURT, Raul. O intercultural: o problema de sua definição. In: CECCHETTI, Elcio; PIOVEZANA, Leonel. (org.) Interculturalidade e educação: saberes, práticas e desafios. Blumenau: Edifurb, 2015.

GEERTZ, Clifford. O saber local: novos ensaios em antropologia interpretativa. Petrópopolis: VOZES, 2009.

GOMES, Luana Barth. Em busca da Yvy Mara Ey (terra sem males): a procura por um território de visibilidade através da interculturalidade. Polis [En línea], [s.l.], v. 38, p. 23xx, 03 sept. 2014. Disponível em: http://journals.openedition.org/polis/10070. Acesso em: 01 out. 2020.

JÁUREGUI, Carlos. Canibalia, calibalismo, antropofagia cultural y consumo em América 
Latina. Habana: CASA Fondo Editorial Casa de Las Américas, 2005.

LÉVI-STRAUS, Claude. Tristes trópicos. Paris: Plon, 1955.

MADERS, Sandra. Educação Escolar Indígena, Intercultura e Formação de Professores. 2017. p. 160. Tese (Doutorado em Educação) - Programa d Pós Graduação em Educação, Universidade Federal de Santa Maria, 2017.

MARIN, José. Educação intercultural: possibilidades para outro futuro. In: CECCHETTI, Elcio; PIOVEZANA, Leonel. (org.) Interculturalidade e educação: saberes, práticas e desafíos. Blumenau: Edifurb, 2015.

MATURANA, Humberto; DÁVILA, Ximena. El árbol de vivir. Santiago: MVP Editores, 2016.

MELIÀ, Bartomeu. La tierra sin mal de los Guaraní: economía y profecía. Paraguay: Brasil; MIMEO, 1987.

MELIÀ, Bartomeu. El guarani conquistado y reducido. Assunção: Centro de Estudos Antropológicos, 1993.

MELIÀ, Bartomeu. El guarani: experiência religiosa. Assunção: Cepag, 1991.

MELIÀ, Bartomeu. A experiência religiosa guarani. In: MARZAL, Manuel M. O rosto índio de Deus. Petrópolis: Vozes, 1989.

PRADO, Paulo. Retrato do Brasil: ensaio sobre a tristeza brasileira. Brasília: IBRASA - INL, 1928.

QUIJANO, Aníbal. Colonialidade do poder, eurocentrismo e América Latina. In: LANDER, R. (org.). A colonialidade do saber: eurocentrismo e ciências sociais: perspectivas latinoamericanas. Buenos Aires: CLACSIO, 2005. Disponível em:

htpp://bibliotecavirtual.clacso.org.ar. Acesso em: 01 out. 2020.

SANTIAGO, Silviano. Uma literatura nos trópicos. 2. ed. Rio de Janeiro: ROCCO, 2000.

TEIXEIRA; Coelho. Moderno pós-moderno. São Paulo: Iluminuras, 2005.

TEIXEIRA; Coelho. A cultura e seu contrário. São Paulo: Iluminuras, 2008.

TEIXEIRA; Coelho. Guerras culturais. São Paulo: Iluminuras, 2000.

TEIXEIRA; Ana Luísa. Educação ameríndia: a dança e a escola Guarani. 1. ed. Rio Grande do 
Sul: EDUNISC, 2009.

TERRA SEM MALES. In: The free encyclopedia. [San Francisco, CA: Wikimedia Foundation, 2020]. Disponível em: https://www.terrasemmales.com.br/. Acesso em: 20 out. 2020.

Recebido em: 29/10/2020

Aprovado em: 18/04/2021

Universidade do Estado de Santa Catarina - UDESC

Centro de Ciências Humanas e da Educação - FAED

PerCursos

Volume 22 - Número 48 - Ano 2021

revistapercursos@gmail.com 